\title{
Sensitivity Optimization of a Microstructured Optical Fiber Ammonia Gas Sensor by means of Tuning the Thickness of a Metal Oxide nano- Coating
}

\author{
Diego López-Torres, Aitor Lopez-Aldaba, Cesar Elosúa Aguado, Jean-Louis Auguste, Raphael Jamier, \\ Philippe Roy, Manuel López-Amo, Senior Member, IEEE and Francisco J. Arregui, Member, IEEE
}

\begin{abstract}
In this paper, the influence of the thickness of metallic-oxide coatings, ITO and $\mathrm{SnO}_{2}$, on the sensitivity of a Microstructured Optical Fiber (MOF) Fabry-Pérot (FP) has been studied with the aim of developing ammonia gas fiber optic sensors. Also, the distribution of the optical power that can be coupled to the metallic-oxide sensing films is investigated in order to understand how the sensor's sensitivity can be improved; the thickness of the coatings plays a relevant role on the sensitivity and response time. Films with thicknesses between 200 and $850 \mathrm{~nm}$ were experimentally examined resulting an optimal thickness of $625 \mathrm{~nm}$ for a $\mathrm{SnO}_{2}$ film. The behavior of the sensors towards different concentrations of ammonia gas from $10 \mathrm{ppm}$ to $130 \mathrm{ppm}$ was analyzed by measuring the phase shifts of the reflected signal using the Fast Fourier Transform (FFT) of its optical spectrum. The registered response/recovery times of this sensor are below 90 seconds.
\end{abstract}

Index Terms - Microstructured Optical Fiber, Fabry-Pérot Interferometer, Ammonia gas, Fast Fourier Transform, Metallicoxides and Thickness.

\section{INTRODUCTION}

THE development of the society and the industry causes that activities as fossil fuel combustions or the utilization of pesticides and fertilizers among others, produce the emission of a high number of gases to the atmosphere [1]-[3]. These gases could be hazardous to human health or environment due to their toxicity and they show an associated risk to the ecosystem. For this reason, the detection of gas molecules such as $\mathrm{NO}_{2}, \mathrm{NH}_{3}$, $\mathrm{NO}$ or $\mathrm{CO}$ is receiving much attention in the last years [4-5].

More specifically, most of the ammonia gas $\left(\mathrm{NH}_{3}\right)$ in the atmosphere is emitted directly or indirectly by human activity[6] [7]. Moreover, in the last years, the worldwide emission of ammonia per year has been increased, reaching the levels set by the European Union (20-30 Tg) to guarantee a good quality of life [8].

Nowadays, there are several areas that require the

This paragraph of the first footnote will contain the date on which you submitted your paper for review. This work was carried out with the financial support of MINECO (Spain) through TEC2016-79367-C2-2-R and TEC 201676021-C2-1-R as well as the FEDER funds and Public University of Navarre program $\mathrm{PhD}$ grants.

D. Lopez-Torres, A. Lopez-Aldaba, C. Elosua, M. Lopez-Amo and F.J. Arregui are with the Department of Electrical, Electronic and Communications Engineering and Institute of Smart Cities, Universidad Publica de Navarra, E- measurement of ammonia concentration in order to prevent hazardous situations for the human being and the environment, in which its concentration varies from parts per million (ppm) [9] to ultra-low concentrations (less than parts per billion (ppb)) [10]. One of them is farming zones [11]-[13]; here, the ammonia emission is due to the utilization of pesticides or fertilizer. Another different area is the automotive and chemical industry; they produce ammonia emissions in many processes developed in their factories [14]; this increment causes that the pollution could reach levels which are a risk for the environment and for the health of the citizen making the commercialization of this type of sensors attractive [15]. And finally, ammonia gas detection is also required in medical applications. As an example, the medical community considers very interesting the detection of ammonia in exhaled air because it can be used for the diagnosis of certain diseases like ulcers, liver or kidney dysfunctions [16]-[18].

Every application mentioned above needs to detect with high accuracy the levels of ammonia. In order to reach ppm-ppb sensitivities, previous papers propose different configurations such as electronic sensors (e-noses) [19-20], non-dispersive sensors [21-22] or spectroscopy [23], [24] based on different sensing principles as, for instance, conducting polymers [2425], colorimetric [27]-[29], absorption [30] or the use of 2-D materials [31]. This paper proposes the use of microstructured optical fibers (MOF) and metallic-oxides with the aim to improving the features of the sensors mentioned above.

As it is widely known, compared to electro-chemical sensors, MOF-gas sensors offer numerous advantages such as electromagnetically passive and immune to electromagnetic interference, lightweight, low cost and wavelength multiplexing which make them ideal candidates for operation in harsh environments with high temperature and humidity. With regard to IR sensors, MOF-gas sensors could work in a wide wavelength range instead of only infrared. For example,

31006 Pamplona, Spain (e-mail: diego.lopez@unavarra.es; aitor.lopez@unavarra.es; cesar.elosua@unavarra.es; mla@unavarra.es; parregui@unavarra.es).

J.-L. Auguste, R. Jamier and P. Roy are with the Fiber Photonics Department, UMR CNRS/University of Limoges 7252, 123 Avenue Albert Thomas, 87060 Limoges cedex, France (e-mail: jean-louis.auguste@xlim.fr; raphael.jamier@xlim.fr; philippe.roy@xlim.fr). 
they can work in the third communication window which they have low transmission losses and the equipment used in this range is more standard and cheaper. Finally, as it can be observed in [32], [33] sensors based on photothermal and photoacoustic spectroscopy need to work set-ups with a high number of components and devices, increasing in this manner, their cost and the possibility that the sensors do not work properly.

For these reasons, metal-oxides have been used for the development and manufacturing of electronic gas sensors, mostly based on $\mathrm{SnO}_{2}$ and ITO [34]-[36]. $\mathrm{SnO}_{2}$ or ITO sensors are rugged, thermally robust, inexpensive and can work in harsh environments such as explosive zones or places with high temperature or humidity. $\mathrm{SnO}_{2}$ is an n-type material (electron donor) which has attractive adsorption properties and also a high chemical and thermal stability in air. ITO also presents these properties: it is a mixture made of indium oxide $\left(\operatorname{In}_{2} \mathrm{O}_{3}\right)$ and tin oxide $\left(\mathrm{SnO}_{2}\right)$, with a typical ratio composition $\left(\mathrm{In}_{2} \mathrm{O}_{3}: \mathrm{SnO}_{2}\right)$ of 90:10 (\%wt). As other metallic oxides, $\mathrm{SnO}_{2}$ and ITO, allow the detection of many gaseous compounds, gases or Volatile Organic Compounds (VOC) among others. But this characteristic does not always have to be taken as a drawback. The low selectivity of the metallic oxides can be very useful in application related to array of sensors or multiplexing. In these cases, with the utilization of post processing techniques such as principal component analysis (PCA) [31], the identification and detection of several gases in complex mixture at the same time can be possible. Moreover, one way to cover the low selectivity of this type of sensors is the surface molecular functionalization [37]; several papers have been demonstrated that thanks to this method, the sensors can be considered as selective towards a specific gas [38]-[40].

In order to explain the mechanism of interaction between gases and metallic-oxides, many models have been proposed. Currently, it is well established that this mechanism is based on the principle of conductance change due to the chemisorption of gas molecules to the sensing layer [7], [41]. Metallic-oxide films consist of a large number of grains, contacting at their boundaries. Its electrical behavior is governed by the formation of double Schottky potential barriers at the interface of adjacent grains caused by charge trapping at the interface; chemisorption of oxygen from air occurs and it causes the immobilization of the electrons of the conduction band of the sensing layer, creating a depletion layer in the near surface. The height of this barrier determines the conductance. When the sensing layer is exposed to a chemically reducing gas, as for example ammonia, co-adsorption and mutual interaction between the gas and the oxygen result in oxidation of the gas at the surface [41]. The removal of oxygen from the grain surface results in a decrease in barrier height. This is a well stablished and accepted model for electronic gas sensors based on metal-oxides which assumes that the molecules of gases penetrate in the sensing layer. In the current work, instead of taking advantage of the electronic properties of the metal oxides, their optical transparency will be exploited. Here, it is assumed that the chemisorption of gas by the metal-oxide will affect also to its optical properties, generally speaking its refractive index. It has been previously studied in the electronic sensors that the gas concentration inside the sensing layer is not constant and decreases as the distance from the external surface increases; a diffusion of the gas concentration occurs inside the sensing layer [42], [43]. This means that the effect of the gas on the sensing material is dependent on the depth from the external surface. Here, an optical sensor is proposed and the interaction of light with the part of the sensing film that is affected by the gas is critical. In order to optimize these devices, it is necessary to study the influence of the thickness of the sensing layer in the sensor performance.

In addition, temperature is another important factor as the chemisorption and the sensitivity of the sensor depends on it. Most of metallic-oxide gas sensors have to be heated up to temperatures over $250{ }^{\circ} \mathrm{C}$ to achieve good sensitivities. This paper propose to work with thin films able to work at room temperature, avoiding the necessity to heat the sensors [44]. At this point it is important to mention that MOF-gas sensors based on metallic oxide nanocoatings are also sensitive to humidity; in [45], the authors studied the performance of these sensors towards different values of relative humidity. In order to minimize the effect of the humidity on sensor's sensitivity, thinking in a final application, a PTFE membrane can be used because which consists of a hydrophobic film permeable for gases, and more concretely, for ammonia molecules.

Since the idea is to take advantage on the optical properties of these metal-oxides, optical fiber it is a very convenient tool to fabricate the sensors. Among the different types of optical fibers, MOF geometry is characterized by a the arrangement of air holes running along the entire length of the fiber, centered on a core [46]. Due to this characteristic, this kind of fibers has attracted an intense research activity and the presence of these air-holes in the cladding offers the opportunity to detect many parameters such as gases, volatile organic compounds (VOCs), among other [45], [47], [48]. A specific type of MOFs is suspended-core MOFs which presents air holes surrounding a small core (typically a few microns diameter). If the goal is to develop gas sensor, these optical fibers have several attractive advantages because it is possible to select the structure of the fiber, more concretely, the dimensions of the holes and core of the fibers used varying the features of the transmitted light; in every different MOF structure developed in this work, the objective is to enhance the evanescent field of the light inside the holes and to improve in this manner, the interaction between this evanescent field and the gases [49].

Taking into account this, the characteristics of suspendedcore MOFs and metallic oxides previously explained, the authors propose the combination of both elements for the development of an ammonia gas sensor. In addition, for the first time, the influence of the metallic oxides film thicknesses in terms of optical power coupled to the sensing film, sensitivity and response time of these suspended-core MOF sensors are studied, making a theoretical study of their optical characteristics and exposing experimentally the sensors to different concentrations of ammonia gas (from $10 \mathrm{ppm}$ to 130 ppm). 


\section{MATERIALS \& METHODS}

\section{A. Construction of the MOF sensor}

As it has been exposed in the introduction, the geometry of suspended core MOFs is very attractive to develop gas sensors. This paper proposes to use a MOF named four-bridge doubleY-shape core fabricated using the stack and draw process. This fiber is formed by four large air holes divided by four bridges (the average width of these four bridges is $819.5 \pm 26.16 \mathrm{~nm}$ ) and shows a suspended core of dimension $1.142 \mu \mathrm{m}$ (height) and 5.942 (width) $\mu \mathrm{m}$, as a double Y shape (see Fig.1.A). This particular structure has interesting properties for gas sensing and chemical deposition processes; the presence of the four longitudinal air holes directly in contact with the fiber core allows the light guided in the core and the surrounding medium to interact directly through the evanescent field; in the same manner, metallic-oxides can be deposited inside these holes as well as on the tip of the fiber using physical deposition, allowing the interaction between them and the evanescent field of the guided light.

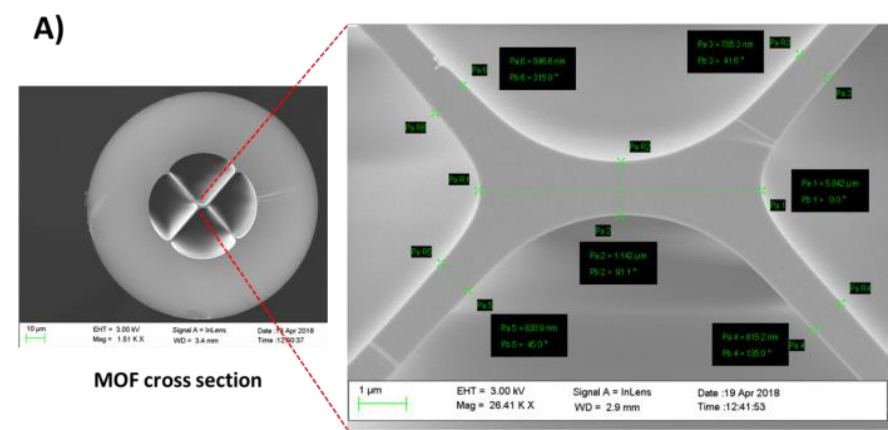

B)

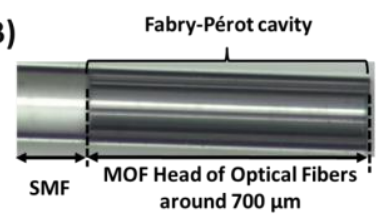

Fig. 1. A): On the left, MOF cross section used to develop ammonia gas sensors; on the right, a zoom of the core with their dimensions. B): Structure of the lowfinesse Fabry-Pérot cavity.

A short length of the four-bridge double-Y-shape core MOF (around $700 \mu \mathrm{m} \pm 10 \mu \mathrm{m}$ ) was used to fabricate a low-finesse Fabry-Pérot (FP) interferometer [50] by splicing it to a singlemode optical fiber Corning SMF-28, as it has been previously explained in [45]. Fig.1.B shows the structure of the FP interferometer.

\section{B. Sensing material}

$\mathrm{SnO}_{2}$ and ITO were selected as the sensing materials due to their good features to develop gas sensors. Both metallic-oxide materials were purchased from ZhongNuo Advanced Material Technology Co. They were deposited onto the heads of the MOF Fabry-Pérot sensors (MOF-FP) using a sputtering machine (Pulsed DC sputtering System, Nadetech Innovations). This technique was selected because it allows controlling with high accuracy the final thickness obtained in every deposition. Moreover, the time of fabrication required to deposit suitable coatings in the desired range is very short, in the order of 5 minutes [51].

\section{Experimental set-ups}

Fig. 2 shows the set up used during the nanofilm construction process. The sensors were placed into the sputtering machine in a vertical position under the ITO or $\mathrm{SnO}_{2}$ target. The sputtering machine was configured with a partial pressure of Argon of $5 \times 10^{-2} \mathrm{mbar}$, a current of $150 \mathrm{~mA}$ and a voltage of 180 $\mathrm{V}$. It is very important to set these parameters for every construction process as well as the distance between the MOF sensor head and the ITO/ $\mathrm{SnO}_{2}$ target in order to guarantee the same construction conditions; in this case, this distance was 5 $\mathrm{cm}$.

The film deposition was monitored using a reflection set up in order to analyze the evolution of the spectrum during the process. This set up was formed by a commercial optical interrogator (Smartec SM 125) which was used to illuminate the sensors and also to record the reflected spectral response. The interrogator was controlled by MATLAB ${ }^{\circledR}$ software (see Fig. 2).

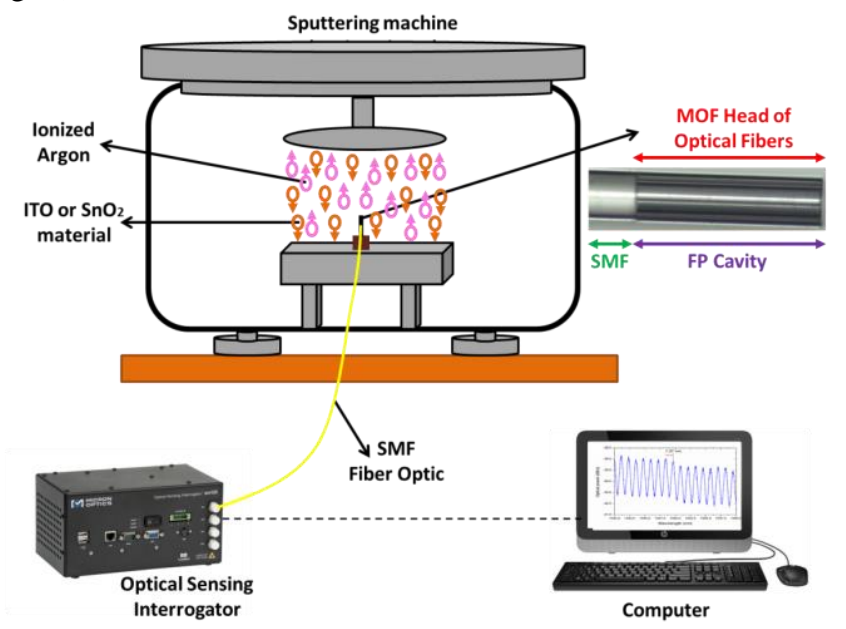

Fig. 2. Reflection set up used to control the construction of the $\mathrm{SnO}_{2} / \mathrm{ITO}$ nanofilm by means of the sputtering technique.

The response of the sensors towards ammonia gas was studied using a measurement set up which is divided into two parts: the first one is formed by the devices needed to record every spectra of the sensor response (the optical fiber reflection configuration shown in Fig. 2); the second one is the part necessary to expose the sensors to different concentrations of ammonia, see Fig. 3. The flow of the gases (ammonia and nitrogen) from gas bottles was controlled by virtual instrumentation (software LabView ${ }^{\circledR}$ ) which regulated the gas flow through EL-Mass Flow Meters (Bronkhorst Inc). Both gas bottles were purchased from Praxair Inc. who certified and ensured the high purity of the gases $(99.999 \%)$. The mixing chamber of the set up is in reality a Controlled Evaporator Mixer (CEM) that allows to control with high accuracy the values of temperature used during the measurement process.

One of the most used techniques for the detection of ammonia gas is based on the $\mathrm{pH}$ variation produced in a sensing material that contains a $\mathrm{pH}$ indicator and water [52]. Since ammonia vapor dissolves in water, this affects the $\mathrm{pH}$ of the sensing medium and indirectly the $\mathrm{pH}$ indicator provides an 
optical signal which is proportional to the $\mathrm{NH}_{3}$ gas concentration. Unfortunately, this type of sensors cannot be used in dry environments because the sensing material would be degraded. Taking this into account, this paper proposes an alternative sensor that can work at $0 \%$ Relative Humidity. In fact, the sensors were exposed to different concentrations of ammonia gas from $10 \mathrm{ppm}$ to $130 \mathrm{ppm}$ using nitrogen dry gas as the carrier at a constant gas flow and temperature of 3512.5 $\mathrm{ml} / \mathrm{min}$ (the SCCM of the gas was $3833.98 \mathrm{~cm}^{3} / \mathrm{min}$ ) and $25^{\circ} \mathrm{C}$ $\pm 0.5^{\circ} \mathrm{C}$, respectively.

In order to avoid any influence from external gases and ensuring the constant value of zero humidity at room temperature, the sensors were placed into a hermetic measurement chamber. This gas calibration system is shown in Fig. 3.

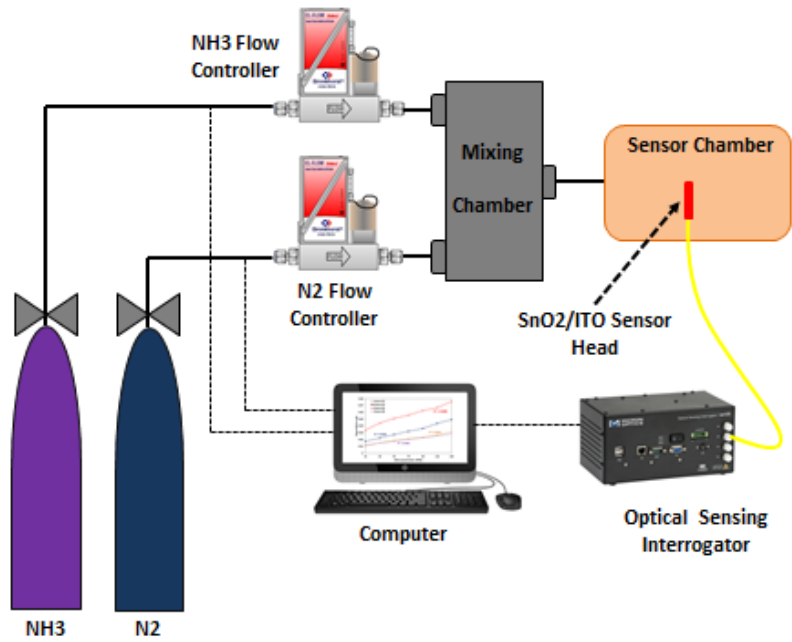

Fig. 3. Set up used where the sensors were exposed to different concentrations of ammonia gas

\section{Theoretical analysis}

To understand the interaction of the evanescent field of the light with the deposited sensing layer (ITO or $\mathrm{SnO}_{2}$ ) and the effect of increasing its thickness, in terms of guided optical power, a numerical study was performed using COMSOL(C) software. The study was performed for a layer thickness range from 0.1 to $11 \mu \mathrm{m}$. In the case of ITO, the refractive index was set at $1.811+\mathrm{j} 0.052$ at $1550 \mathrm{~nm}$ (it is the typical wavelength used in third window equipment); for $\mathrm{SnO}_{2}$ thin films, the refractive index was set at $1.901+\mathrm{j} 0.022$ at $1550 \mathrm{~nm}$. These values were experimentally obtained when ITO and $\mathrm{SnO}_{2}$ were deposited on a glass slide by means of sputtering technique with the same parameters explained in section 2.3 and afterwards, their refractive indexes were measured using an ellipsometer, Uvisel 2 (Horiba).

In this work, a standard communications single mode fiber (SMF) is experimentally spliced to the MOF $(10.2 \mu \mathrm{m}$ of modal diameter). Due to this, for the theoretical analysis it is assumed a Gaussian electric field following the SMF LP01 fundamental mode at $1550 \mathrm{~nm}$. This excitation model has been also verified by using a two-step mode analysis: firstly, a SMF is simulated and its LP01 modal distribution is obtained and used as input value for the second step: the MOF fiber. This two-step process is a key point for the theoretical analysis because, as it will be seen, the Gaussian input modal field diameter determines the guided optical power and limits the effective dimensions of the fiber core.

\section{RESULTS \& DISCUSSION}

\section{A. Study of theoretical simulations}

In this section, the results obtained by simulations with COMSOL(C) software are exposed. It is important to mention that all the theoretical results obtained with ITO and $\mathrm{SnO}_{2}$ as well were analogous (little variations on the effective refractive indexes of each propagated mode but no field distribution differences). For this reason, the authors decided to show only the graphs of the ITO study for the shake of clarity; Fig. 4 shows the modal field distribution of the fundamental mode $\mathrm{LP}_{01}$ for ITO thin films of $300 \mathrm{~nm}, 500 \mathrm{~nm}$ and $700 \mathrm{~nm}$ thickness.
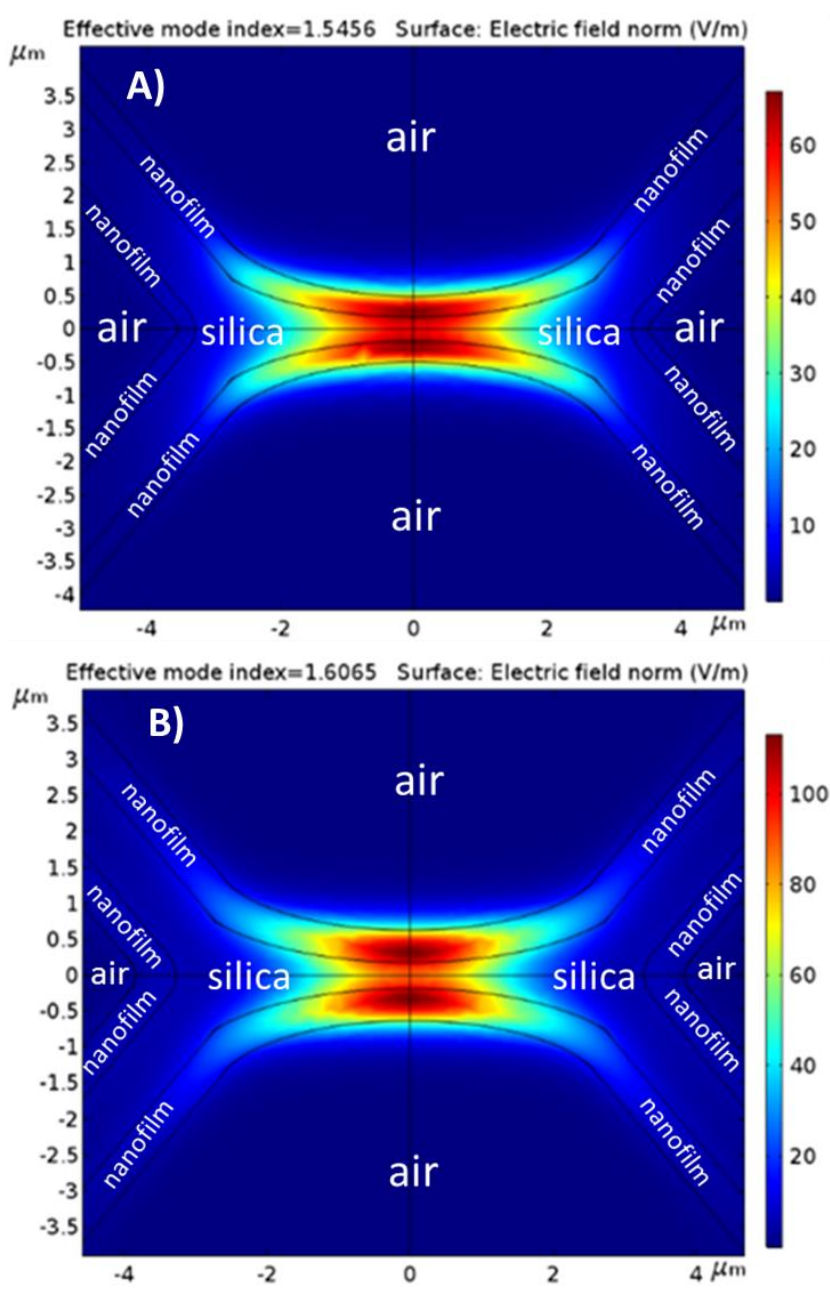


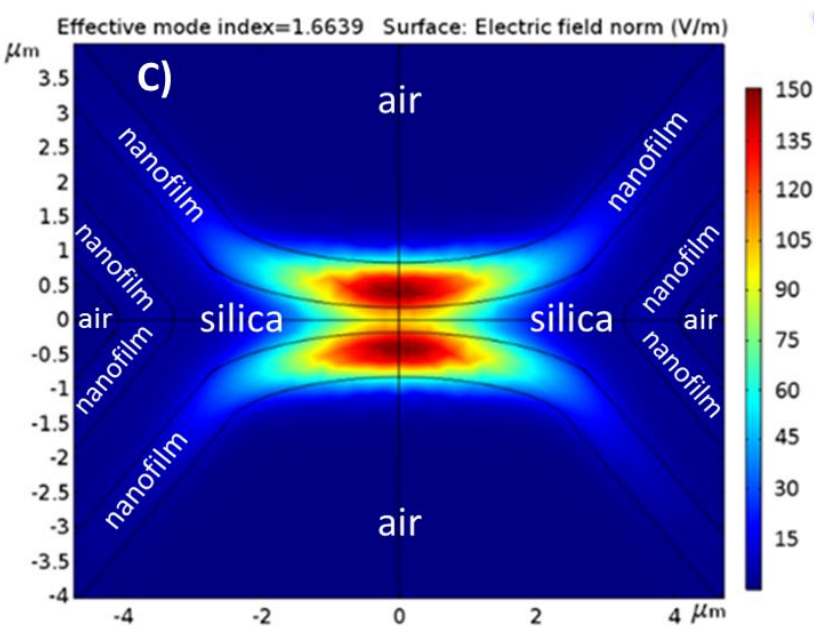

Fig. 4. $\mathrm{LP}_{01}$ distributions for ITO thin film layers: A) $300 \mathrm{~nm}$, B) $500 \mathrm{~nm}$ and C) $700 \mathrm{~nm}$.

The first phenomenon that it can be noticed is the field confinement with the deposition thickness. For thinner ITO nanofilms (below $300 \mathrm{~nm}$ ), the mode field distribution is not only confined inside the ITO film but also expands inside the silica substrate.

For thicker ITO thicknesses, the optical power remains mainly inside the nanofilm; its behavior is similar to an isolated one-layer antiresonant reflecting optical waveguide (ARROW) propagating structures [53]. Since $\mathrm{n}_{\text {core }}<\mathrm{n}_{\text {cladding }}$ (where core is made of silica and cladding of ITO), these structures would support leaky-mode propagation [54].

The second conclusion is the relation between the sensing layer thickness and the optical power that this layer can guide. This relationship was measured by integrating the optical power inside the thin film waveguides. Results of this study are shown in Fig. 5 in order to verify the ARROW guide performance.

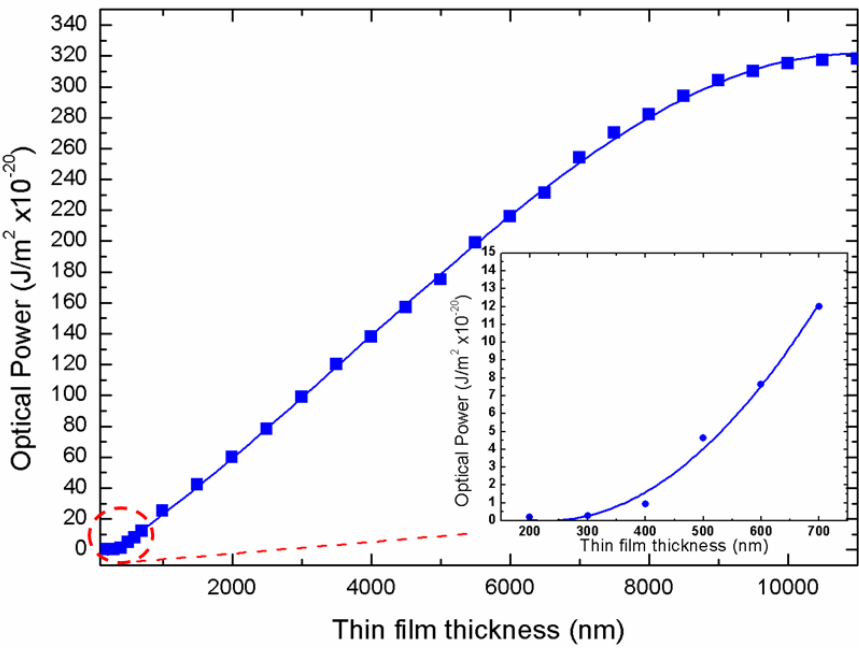

Fig. 5. Guided optical power by the thin film against film thickness; the inset is a zoom of the guided optical power behavior in thinner thicknesses.

The optical power guided inside the thin film follows an exponential relation with the ITO thin film for a deposition thickness below $1 \mu \mathrm{m}$, see inset of Fig. 5. For thicker layers, the integrated optical power rises as the ARROW guide fits the input modal field diameter until it reaches its highest value close to $\sim 10 \mu \mathrm{m}$ of modal diameter. Beyond this value, the optical power remains almost constant as all the input power is guided through the ARROW optical guide.

To explain the sensing mechanism of these sensors with ammonia gas, a hypothesis can be inferred: there could be two main phenomena affecting the sensitivity. On the one hand, the refractive index variation induced by the gas penetration. This variation is caused by the penetration of the gas molecules in the sensing layer and it is expected not to be uniform because the presence of gas should be higher in regions closer to the sensing layer-gas interface; consequently, there is a gradient of gas penetration inside the sensing layer. The thicker the sensing layer is, the lower is the relative penetration (gas molecules can penetrate until one determined depth for a given concentration, independently of the sensing layer thickness). On the other hand, from the numerical simulations, it has been inferred that as the sensing layer grows, more optical power is guided through it until a certain value. Thus, there is a trade-off between the sensing layer thickness and the sensor sensitivity achieved. For thinner nanofilms, the refractive index variation of the layer due to gas penetration is higher in comparison with thicker nanofilms (with lower relative penetration of gas) but on the other hand, the guided optical power by these nanofilms is lower than the guided by thicker nanofilms. The optimal thickness is difficult to obtain just through the numerical analysis because this simulation does not link the layer thickness with the sensor sensitivity and also does not take into account the effect of the penetration of the ammonia into the sensing nanofilm. An experimental study is needed in order to combine both theoretical results and provide an optimal thickness.

\section{B. Construction of the nanofilm}

In order to find the optimal thickness that satisfies, in the most appropriate way, the trade-off between guided optical power and depth penetration of gas molecules, two different sets of sensors were fabricated with ITO and $\mathrm{SnO}_{2}$. The metallic-oxides were deposited onto the heads of the MOF-FP sensors using the sputtering technique described in section 2.2.

These two sets consisted of 4 sensors with different thicknesses and consequently, different construction times. The times selected were 2, 4, 6 and 8 minutes always setting the conditions exposed in section 2.2. These times were selected with the intention to obtain and to study the behavior of thicknesses, in the range of 0.1-1 micrometers. The ITO sensors were named ITO227 (2 minutes of deposition), ITO331 (4 minutes of deposition) and so on; the $\mathrm{SnO}_{2}$ sensors were called in the same manner, firstly the metallic oxide used and secondly the thickness of the sensor $\left(\mathrm{SnO}_{2} 192\right.$ for 2 minutes of deposition), see Table 1. The thicknesses of the two sets of sensors were measured by Scanning Electronic Microscope (SEM), confirming that the thicknesses obtained were in the suitable range. 


\begin{tabular}{|c|c|c|}
\hline Material & Deposition time (minutes) & Thickness (nm) \\
\hline \multirow{3}{*}{ ITO } & 2 & $227 \pm 23$ \\
& 4 & $331 \pm 13$ \\
& 6 & $435 \pm 31$ \\
\hline & 8 & $797 \pm 28$ \\
\hline \multirow{3}{*}{ SnO2 } & 2 & $192 \pm 11$ \\
& 4 & $405 \pm 21$ \\
& 6 & $625 \pm 17$ \\
\hline
\end{tabular}

Table. 1. Summary of the different features of the sensors and their names.

Based on the fact that the structure of the MOFs (core and bridges) did not always present the same dimensions (due to the custom fabrication process as it is not a commercial fiber, see Fig. 1.A), the width of each of the 4 bridges of a same MOFs was measured and averaged prior to the nanocoating deposition in order to minimize the possible error in this measurement. After the nanocoating deposition, the average width of the bridges was measured again; subtracting both values (average width before and after deposition) the thickness of the coating was determined (see Fig. 6). The results obtained are showed in Table 1 with their corresponding standard deviations.
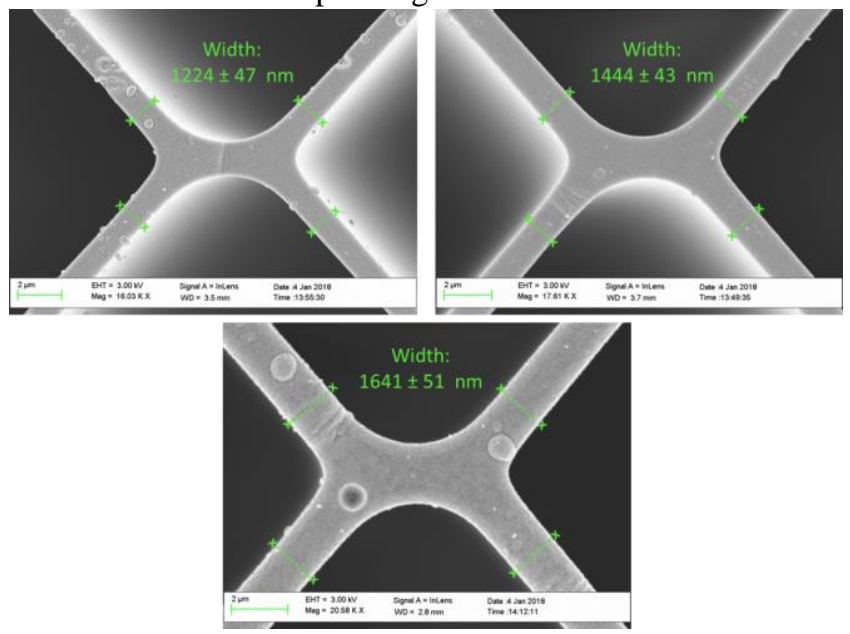

Fig. 6. Details of $\mathrm{SnO}_{2} 405, \mathrm{SnO}_{2} 625$ and $\mathrm{SnO}_{2} 822$ cross sections after $\mathrm{SnO}_{2}$ deposition. The nanofilm thicknesses were measured by a Scanning Electronic Microscope (SEM) in the specific point fixed with the dotted lines and the crosses.

\section{Characterization of the sensors toward ammonia gas}

Another way to verify that metal oxides have been properly deposited is to analyze the interferometric response of the sensors. Fig. 7 shows the spectrum of the $\mathrm{SnO}_{2} 625$ before (in red) and after (in blue) nanofilm deposition process. It can be appreciated that during this process, a wavelength shift occurs (every peak of the spectrum suffers a red shift; in Fig. 7, it is indicated with red arrows), confirming the assumption that metallic-oxides, ITO or $\mathrm{SnO}_{2}$, are deposited inside the holes and on the tip of the MOF-FP sensors.

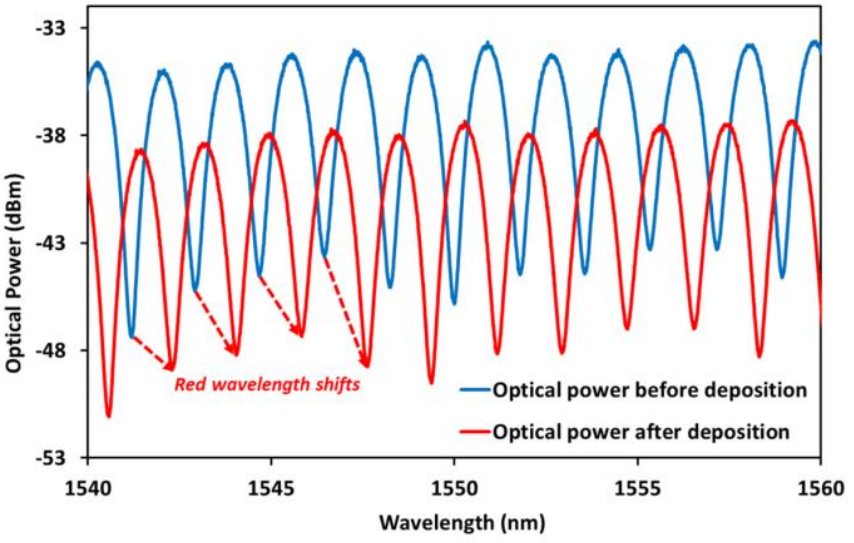

Fig. 7. In blue, the FP interference obtained for $\mathrm{SnO}_{2} 625$ just after the splice between SMF and MOF with no coating; in red, the optical power of $\mathrm{SnO}_{2} 625$ measured with the optical interrogator after deposition process.

Thanks to the features of the spectra of the sensors after nanofilm deposition process (showed in Fig. 7), it is possible to apply the Fast Fourier Transform (FFT) as method of characterization of the sensor response towards ammonia gas. This technique has been explained in [55] and it shows several improvements over techniques based on the tracking of the wavelength shifts [56]; one of the most important is that this method does not depend of the signal amplitude and for this reason, amplitude variations have not got any influence on the data processing making it easier.

The refractive index of the external medium changes when the sensors are exposed to different concentrations of ammonia as well as the refractive index of the sensing layer; a very important consequence of this fact is that a phase shift occurs. But this variation in the refractive index of the sensing layer is not uniform and it depends on the penetration of the ammonia molecules into this layer. It means that setting a value of ppm, thicker sensing layers present lower relative depth penetration of ammonia molecules and consequently, a lower refractive index variation in the whole layer. But on the other hand, as it can be observed in section 3, thicker thicknesses have the feature to guide more optical power. Based on these phenomena, and with the aim of obtaining a suitable nanofilm that gives the best sensitivity possible, sensors with different thicknesses were exposed to ammonia gas using the set up showed in Fig. 3. Firstly, $\mathrm{SnO}_{2}$ sensors were exposed to 130, 110, 90, 70, 50, 30 and $10 \mathrm{ppm}$ of ammonia gas. Fig. 8 shows the calibration curves of the $\mathrm{SnO}_{2}$ sensors with the corresponding phase shifts measured when they were exposed to these concentrations: the solid shapes in the graphic represent the experimental data and the color lines correspond to the practical values, calculated according to a statistical approximation. It can be appreciated that the highest phase shift when the sensors were exposed to the lowest ammonia concentration, $10 \mathrm{ppm}$, was $\mathrm{SnO}_{2} 625$ with a phase shift of 0.034 $\pi$ radians; it was the sensor with the best sensitivity. At this point, it is important to remark that $10 \mathrm{ppm}$ is the lowest value that the authors can obtain with their set up but it is not the lowest ammonia detection value of $\mathrm{SnO}_{2} 625$; this result encourages the authors to think that the system could be 
enhanced to measure concentrations in the range of ppb. Regarding to maximum detectable gas concentration, similar sensors were exposed to saturated atmospheres of acetone, isopropanol and methanol with a good behavior [57]. For the thickest $\left(\mathrm{SnO}_{2} 822\right)$ and thinnest $\left(\mathrm{SnO}_{2} 192\right)$ thicknesses, their sensitivities were the worst and the phase shifts measured for this concentration $(10 \mathrm{ppm})$ were almost the same, $0.011 \pi$ radians. In the case of $\mathrm{SnO}_{2} 192$, the sensing layer is very thin and for this reason, the optical power guided by this layer is very low and it is necessary to couple more to achieve better sensitivities. The case of $\mathrm{SnO}_{2} 822$ is the opposite; the optical power coupled is very high because the thickness of the sensing layer is thick but the relative depth penetration of ammonia molecules into the sensing layer is very low with regard to its thickness and consequently, the total variation of the sensing layer refractive index is also low. $\mathrm{SnO}_{2} 405$ shows a phase shift of $0.017 \pi$ radians when it was exposed to $10 \mathrm{ppm}$ of ammonia gas. This sensor has not got the best sensitivity possible because there exist thicker thicknesses which can couple more optical power and the diffusion of the ammonia gas molecules into them gives refractive index changes sufficiently high to improve $\mathrm{SnO}_{2} 405$ sensitivity (as it the case of $\mathrm{SnO}_{2} 625$ ). As it can be also appreciated in Fig. 8, the R2 values obtained for $\mathrm{SnO}_{2}$ sensors are always higher than $0.9888\left(\mathrm{SnO}_{2} 625\right.$ value $)$, confirming that the statistical approximation used is a good adjustment model for $\mathrm{SnO}_{2}$ sensor responses towards ammonia.

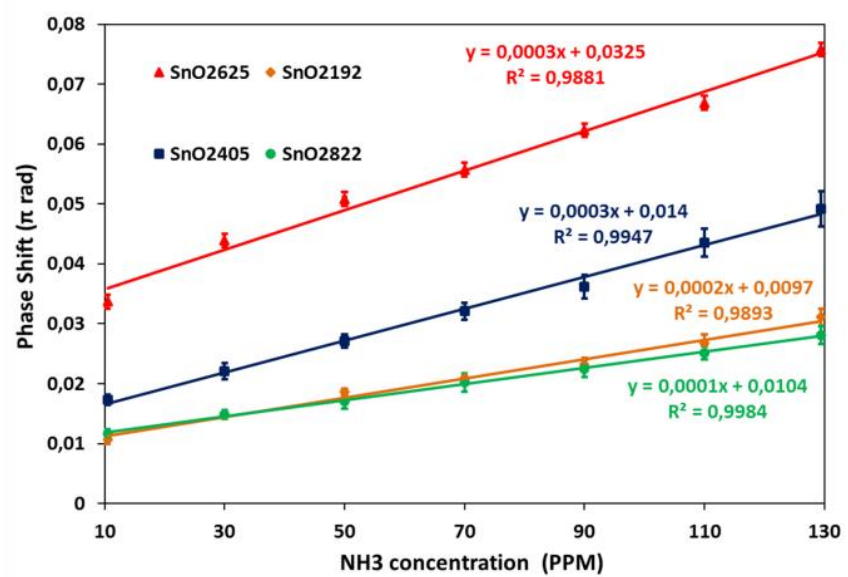

Fig. 8. Calibration curves with their errors obtained for the sensors with a $\mathrm{SnO}_{2}$ sensing layer when they were exposed to different concentration to ammonia gas, from $130 \mathrm{ppm}$ to $10 \mathrm{ppm}$.

ITO sensors were also exposed to the same concentrations of ammonia gas (from $130 \mathrm{ppm}$ to $10 \mathrm{ppm}$ ) in order to compare the sensibilities of the different metallic-oxides, $\mathrm{SnO}_{2}$ and ITO. Fig. 9 shows, in the same manner that Fig. 8, the phase shifts measured for ITO sensors when they were exposed to these concentrations of ammonia gas. ITO435 showed the best sensitivity for ITO nanofilms with a phase shift of $0.0064 \pi$ radians for $10 \mathrm{ppm}$ of ammonia gas; ITO331 and ITO227 showed $0.0053 \pi$ radians and $0.0041 \pi$ radians, respectively. As it can be observed, $\mathrm{SnO}_{2} 625$ is more sensitive than ITO435 improving its sensitivity five times. It means that $\mathrm{SnO}_{2}$ is more appropriate to develop this type of ammonia gas sensors than
ITO. Regarding to R2 values, the lowest value for ITO Sensors was 0.9961 (ITO331), also confirming that the linear model fits in an acceptable way.

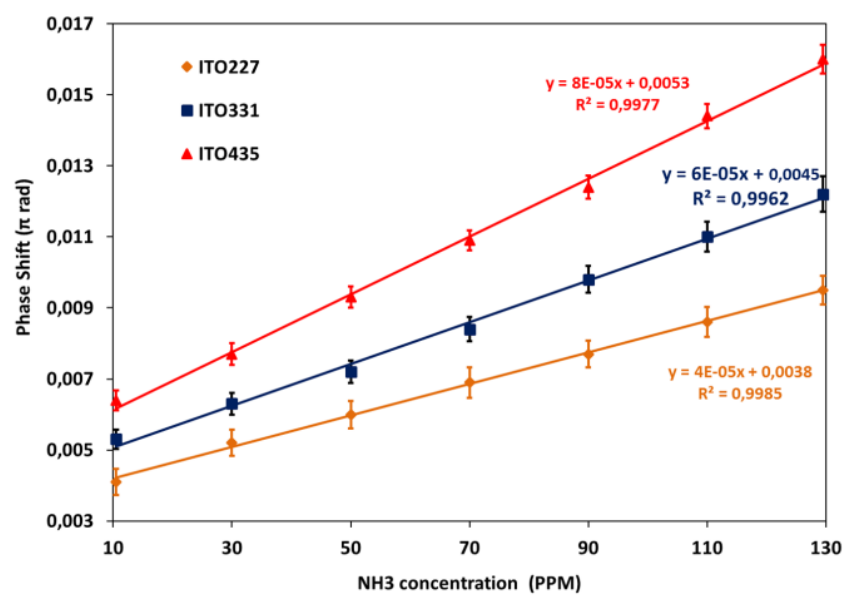

Fig. 9. Calibration curves with their errors obtained for the sensors with an ITO sensing layer when they were exposed to different concentration to ammonia gas, from $130 \mathrm{ppm}$ to $10 \mathrm{ppm}$.

The dynamic behavior of ITO435 and $\mathrm{SnO}_{2} 625$, when they were exposed towards ammonia gas, is showed in Fig. 10. It can be inferred that the sensitivities of both sensors are different. Both responses are repetitive and after every exposure, the sensors always recovered the baseline in a short period of time. This behavior is possible thanks to the holey structure of the four-bridge double-Y-shape core fiber used in this work; the holes of this particular MOF allow a quickly adsorption and desorption of ammonia gas molecules obtaining short response and recovery times (see Table 2). More precisely, ITO435 showed faster recovery times than $\mathrm{SnO}_{2} 625$ in every exposure (see Table 2); in both cases, the longest recovery times values (ITO435, 70 seconds and $\mathrm{SnO}_{2} 625,75$ seconds, respectively) were obtained when the sensors were exposed to the highest ammonia gas concentration. When the sensors were exposed to lowest ammonia gas concentrations, the recovery times measured were shorter than these values (45 seconds for ITO435 and 70 seconds for $\mathrm{SnO}_{2} 625$ ). Regarding to response times, ITO435 was also faster than $\mathrm{SnO}_{2} 625$ (see Table 2). ITO435 showed times shorter than 35 seconds in every exposure in comparison with $\mathrm{SnO}_{2} 625$ which showed 75 seconds. As in the case of recovery time, this response corresponds to the highest value of ammonia gas concentration.

\begin{tabular}{|c|c|c|c|c|c|c|c|c|}
\cline { 2 - 8 } \multicolumn{1}{c|}{} & \multicolumn{7}{c|}{ Response Times (s) } \\
\cline { 2 - 9 } \multicolumn{1}{c|}{} & $130 \mathrm{ppm}$ & $110 \mathrm{ppm}$ & $90 \mathrm{ppm}$ & $70 \mathrm{ppm}$ & $50 \mathrm{ppm}$ & $30 \mathrm{ppm}$ & $10 \mathrm{ppm}$ \\
\hline ITO435 & 35 & 35 & 30 & 28 & 25 & 25 & 22 \\
\hline SnO2625 $^{4}$ & 75 & 55 & 53 & 50 & 48 & 53 & 55 \\
\cline { 2 - 8 } & \multicolumn{7}{|c|}{ Recovery Times (s) } \\
\cline { 2 - 9 } & $130 \mathrm{ppm}$ & $110 \mathrm{ppm}$ & $90 \mathrm{ppm}$ & $70 \mathrm{ppm}$ & $50 \mathrm{ppm}$ & $30 \mathrm{ppm}$ & $10 \mathrm{ppm}$ \\
\hline ITO435 & 70 & 70 & 70 & 65 & 60 & 50 & 45 \\
\hline $\mathrm{SnO}_{2625}$ & 75 & 75 & 75 & 73 & 75 & 72 & 70 \\
\hline
\end{tabular}

Table. 2. Comparative between $\mathrm{SnO}_{2} 625$ and ITO435 responses and recovery times measured when they were exposed to different concentration of ammonia gas, from 130 to $10 \mathrm{ppm}$. 


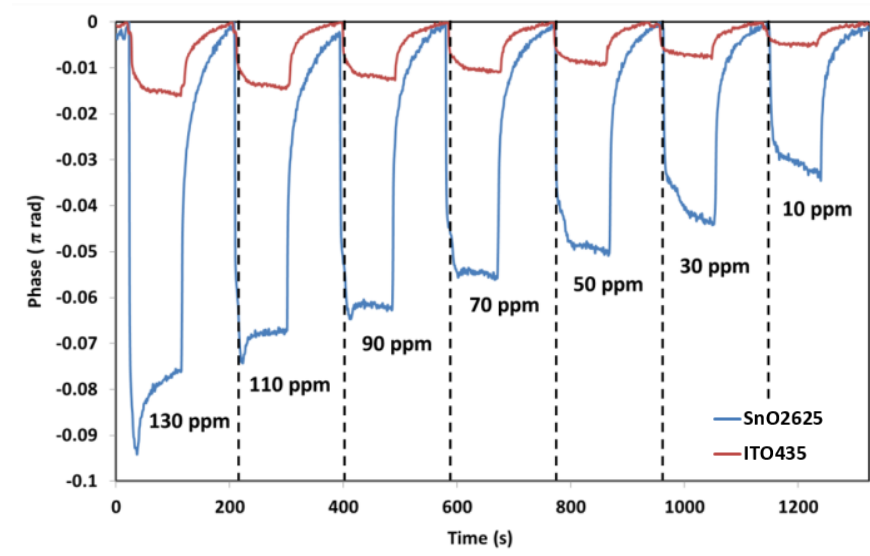

Fig. 10. Comparative between $\mathrm{SnO}_{2} 625$ and ITO435 phase responses measured when they were exposed to different concentration of ammonia gas, from 130 ppm to $10 \mathrm{ppm}$.

In order to facilitate the comparison between the response and recovery times of the sensors exposed in Table. 2, Fig. 11 is showed. In this graph, the main $\mathrm{Y}$ axis represents the response times of the sensors (in seconds) and the secondary, the recovery times (also in seconds); $\mathrm{X}$ axis represents the different concentrations of ammonia which the sensors were exposed. The arrow direction of the dotted circle indicates the axis which the measurement corresponds, response time or recovery time, respectively. As in the case of Table.2, it is easily appreciable that the response and recovery times of the ITO435 sensor are always faster than $\mathrm{SnO}_{2} 625$ when the sensors are exposed to the same concentration of ammonia gas.

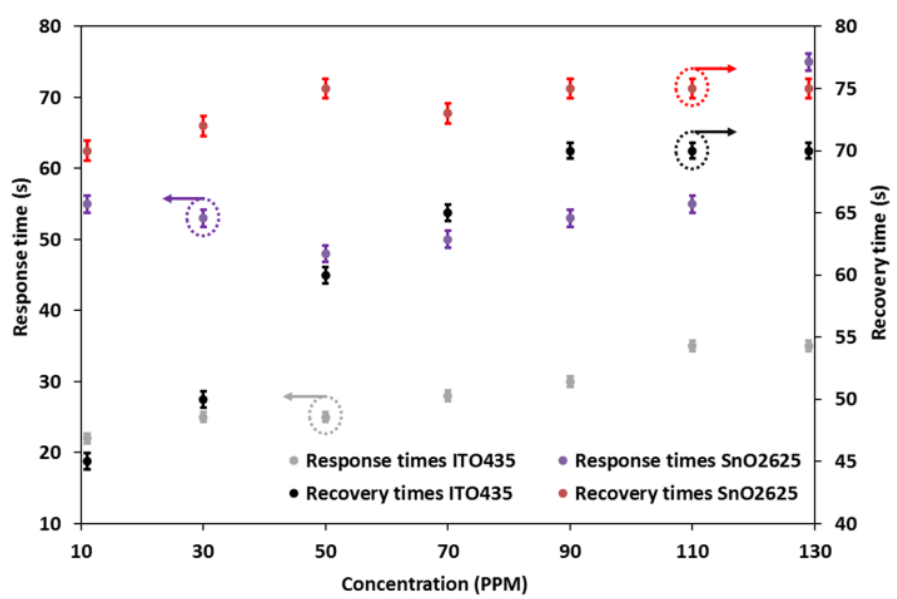

Fig. 11. Response (principal axis) and recovery times (secondary axis) of $\mathrm{SnO}_{2} 625$ and ITO435 when they were exposed to 130 and $10 \mathrm{ppm}$ of $\mathrm{NH}_{3}$.

Fig.11 is a zoom of Fig.10 and it shows the recovery and response times of ITO435 and $\mathrm{SnO} 2625$ when they was exposed to $50 \mathrm{ppm}$ and $30 \mathrm{ppm}$ of ammonia gas in order to show the dynamic behavior of the sensors.

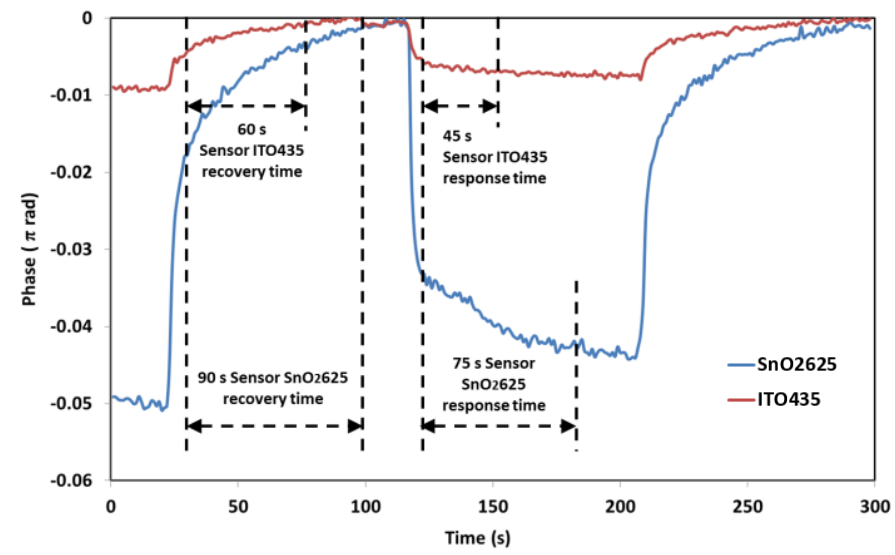

Fig. 12. Recovery and response times of $\mathrm{SnO}_{2} 625$ and ITO435 when they were exposed to 50 and $30 \mathrm{ppm}$ of $\mathrm{NH}_{3}$, respectively.

\section{CONCLUSION}

In this paper, a study of the thickness influence of metallicoxide coatings, ITO and $\mathrm{SnO}_{2}$ on the sensitivity of a MOF-FP ammonia gas is presented. The results of this paper corroborate that thickness is a key aspect to optimize the sensitivity.

The thickness plays this important role because two very parameters depend on it in a very high way. The first parameter is the optical power that a specific structure (formed by a MOF and a sensing layer deposited on it) can guide or couple; the second parameter is the diffusion of the gas molecules inside this layer by means of the chemisorption. For this reason, this paper concludes that it is necessary to reach a trade-off between the optical power that a structure can guide through its sensing layer deposited and the influence that the gas molecules of $\mathrm{NH}_{3}$ has in this layer and consequently, in its effective refractive index.

The feasibility of metallic-oxides as ammonia gas sensing material has been also studied and two of the most used, ITO and $\mathrm{SnO}_{2}$, were compared concluding that $\mathrm{SnO}_{2}$ has best sensitivity to this gas than ITO.

It has been experimentally probed that the combination of MOF-FP and metallic-oxides deposited by means of sputtering technique is a good election to develop this type of gas sensor. The sensor that exhibited the best sensitivity, a MOF-FP sensor with a $\mathrm{SnO}_{2}$ coating of $625 \mathrm{~nm}\left(\mathrm{SnO}_{2} 625\right)$, showed a phase shift of $0.034 \pi$ radians when it was exposed to an ammonia concentration of $10 \mathrm{ppm}$. Moreover, the sensor response was repetitive and after every exposure (from $130 \mathrm{ppm}$ to $10 \mathrm{ppm}$ ), the sensor reached its baseline in a short period of time with suitable recovery and response times of 75 and 53 seconds respectively at room temperature.

\section{REFERENCES}

[1] N. Docquier and S. Candel, "Combustion control and sensors: A review," Prog. Energy Combust. Sci., vol. 28, no. 2, pp. 107-150, 2002.

[2] J. Riegel, "Exhaust gas sensors for automotive emission control," Solid State Ionics, vol. 152-153, pp. 783-800, 2002.

[3] S. Ampuero and J. O. Bosset, "The electronic nose applied to dairy products: A review," Sensors Actuators, B Chem., vol. 94, no. 1, pp. $1-12,2003$.

[4] H. Services, "U . S . D EPARTMENT OF HEALTH AND HUMAN SERVICES Agency for Toxic Subst . ances a n d Disease 
R. Atkinson, "Atmospheric chemistry of VOCs and $\mathrm{NO}(\mathrm{x})$," Atmos. Environ., vol. 34, no. 12-14, pp. 2063-2101, 2000.

[6] P. Warneck, "Chemistry of the Natural Atmosphere," Acad. Press Inc., Oct. 1988.

[7] B. Timmer, W. Olthuis, and A. Van Den Berg, "Ammonia sensors and their applications - A review," Sensors Actuators, B Chem., vol. 107, no. 2, pp. 666-677, 2005

[8] J. R. ISTAS, R. DE BORGER, L. DE TEMMERMAN, GUNS, K. MEEUS-VERDINNE, A. RONSE, P. SCOKART, and M. TERMONIA, "Effect of Ammonia on the acidification os the anvironmental," Acad. Press Inc., 1988.

[9] R. Kincaid, K. Johnson, G. H. Mount, D. Yonge, J. Havig, H. Westberg, B. Lamb, and B. Rumburg, "Measurement of atmospheric ammonia at a dairy using differential optical absorption spectroscopy in the mid-ultraviolet," Atmos. Environ., vol. 36, no. 11, pp. 1799-1810, 2002.

[10] J. W. Erisman, R. Otjes, A. Hensen, P. Jongejan, P. Van Den Bulk, A. Khlystov, H. Möls, and S. Slanina, "Instrument development and application in studies and monitoring of ambient ammonia," Atmos. Environ., vol. 35, no. 11, pp. 1913-1922, 2001.

[11] J. Fernández-Seara, J. Sieres, and M. Vázquez, "Distillation column configurations in ammonia-water absorption refrigeration systems," Int. J. Refrig., vol. 26, no. 1, pp. 28-34, 2003.

[12] P. Colonna and S. Gabrielli, "Industrial trigeneration using ammonia-water absorption refrigeration systems (AAR)," Appl. Therm. Eng., vol. 23, no. 4, pp. 381-396, 2003.

[13] A. T. Bulgan, "Use of low temperature energy sources in aquaammonia absorption refrigeration systems," Energy Convers. Manag., vol. 38, no. 14, pp. 1431-1438, 1997.

[14] C. Pijolat, C. Pupier, M. Sauvan, G. Tournier, and R. Lalauze, "Gas detection for automotive pollution control," Sensors Actuators, B Chem., vol. 59, no. 2, pp. 195-202, 1999.

[15] A. K. Mallik, G. Farrell, D. Liu, V. Kavungal, Q. Wu, and Y. Semenova, "Silica Gel Coated Spherical Micro resonator for UltraHigh Sensitivity Detection of Ammonia Gas Concentration in Air," Sci. Rep., vol. 8, no. 1, pp. 2-11, 2018.

[16] D. J. Kearney, T. Hubbard, and D. Putnam, "Breath ammonia measurement in Helicobacter pylori infection," Dig. Dis. Sci., vol. 47, no. 11, pp. 2523-2530, 2002.

[17] L. R. Narasimhan, W. Goodman, and C. K. N. Patel, "Correlation of breath ammonia with blood urea nitrogen and creatinine during hemodialysis," Proc. Natl. Acad. Sci., vol. 98, no. 8, pp. 4617-4621, 2001.

[18] E. Verpoorte, "Microfluidic chips for clinical and forensic analysis," Electrophoresis, vol. 23, no. 5, pp. 677-712, 2002.

[19] A. D. Wilson and M. Baietto, "Advances in electronic-nose technologies developed for biomedical applications," Sensors, vol. 11, no. 1, pp. 1105-1176, 2011.

[20] Y. S. Kim, S. C. Ha, Y. Yang, Y. J. Kim, S. M. Cho, H. Yang, and Y. T. Kim, "Portable electronic nose system based on the carbon black-polymer composite sensor array," Sensors Actuators, $B$ Chem., vol. 108, no. 1-2 SPEC. ISS., pp. 285-291, 2005.

[21] W. Nyack, "Tigecycline F. G . 1," vol. 2, no. 12, 2010.

[22] I. M. P. Doyle, G. Dale, H. Choi, and B. City, "UnIted States Patent," vol. 2, no. 12, 2012.

[23] J. P. Dakin, H. O. Edwards, and B. H. Weigl, "Progress with optical gas sensors using correlation spectroscopy," Sensors Actuators B. Chem., vol. 29, no. 95, pp. 87-93, 1995.

[24] N. Joshi, V. Saxena, A. Singh, S. P. Koiry, A. K. Debnath, M. M. Chehimi, D. K. Aswal, and S. K. Gupta, "Flexible H2S sensor based on gold modified polycarbazole films," Sensors Actuators, B Chem., vol. 200, pp. 227-234, 2014.

[25] U. Lange, N. V. Roznyatovskaya, and V. M. Mirsky, "Conducting polymers in chemical sensors and arrays," Anal. Chim. Acta, vol. 614, no. 1, pp. 1-26, 2008.

[26] H. Bai and G. Shi, "Gas Sensors Based on Conducting Polymers," Sensors, vol. 7, pp. 267-307, 2007.

[27] J. Long, J. Xu, Y. Yang, J. Wen, and C. Jia, “A colorimetric array of metalloporphyrin derivatives for the detection of volatile organic compounds," Mater. Sci. Eng. B, vol. 176, no. 16, pp. 1271-1276, Sep. 2011.

[28] J. Courbat, D. Briand, J. Wöllenstein, and N. F. de Rooij, "Colorimetric gas sensors based on optical waveguides made on plastic foil," Procedia Chem., vol. 1, no. 1, pp. 576-579, 2009.
A. Amirjani and D. H. Fatmehsari, "Colorimetric detection of ammonia using smartphones based on localized surface plasmon resonance of silver nanoparticles," Talanta, vol. 176, no. April 2017, pp. 242-246, 2018.

[30] G. Stewart, W. Jin, and B. Culshaw, "Prospects for fibre-optic evanescent-field gas sensors using absorption in the near-infrared," Sensors Actuators B Chem., vol. 38, no. 1-3, pp. 42-47, 1997.

[31] K. Xu, C. Fu, Z. Gao, F. Wei, Y. Ying, C. Xu, and G. Fu, "Nanomaterial-based gas sensors: A review," Instrum. Sci. Technol., vol. 46, no. 2, pp. 115-145, 2018.

[32] V. Spagnolo, A. A. Kosterev, L. Dong, R. Lewicki, and F. K. Tittel, "NO trace gas sensor based on quartz-enhanced photoacoustic spectroscopy and external cavity quantum cascade laser," Appl. Phys. B Lasers Opt., vol. 100, no. 1, pp. 125-130, 2010.

[33] F. A. N. Y. Ang, Y. A. T. An, W. E. I. J. In, Y. U. L. In, and Y. Q. I. Un, "Hollow-core fiber Fabry - Perot photothermal gas sensor," Opt. Lett., vol. 41, no. 13, pp. 3025-3028, 2016.

[34] C. Wang, L. Yin, L. Zhang, D. Xiang, and R. Gao, "Metal oxide gas sensors: Sensitivity and influencing factors," Sensors, vol. 10, no. 3, pp. 2088-2106, 2010.

[35] F. Gyger, M. Hübner, C. Feldmann, N. Barsan, and U. Weimar, "Nanoscale SnO2hollow spheres and their application as a gassensing material," Chem. Mater., vol. 22, no. 16, pp. 4821-4827, 2010.

[36] J. C. Belmonte, J. Manzano, J. Arbiol, A. Cirera, J. Puigcorbé, A. Vilà, N. Sabaté, I. Gràcia, C. Cané, and J. R. Morante,

"Micromachined twin gas sensor for $\mathrm{CO}$ and O2quantification based on catalytically modified nano-SnO2," Sensors Actuators, B Chem., vol. 114, no. 2, pp. 881-892, 2006.

[37] A. Singh, Z. Salmi, N. Joshi, P. Jha, A. Kumar, H. Lecoq, S. Lau, M. M. Chehimi, D. K. Aswal, and S. K. Gupta, "Photo-induced synthesis of polypyrrole-silver nanocomposite films on $\mathrm{N}$-(3trimethoxysilylpropyl)pyrrole-modified biaxially oriented polyethylene terephthalate flexible substrates," $R S C A d v$., vol. 3, no. 16, pp. 5506-5523, 2013.

[38] X. Liu, T. Ma, N. Pinna, and J. Zhang, "Two-Dimensional Nanostructured Materials for Gas Sensing," Adv. Funct. Mater., vol. 27, no. 37, pp. 1-30, 2017.

[39] N. Joshi, T. Hayasaka, Y. Liu, H. Liu, O. N. Oliveira, and L. Lin, "A review on chemiresistive room temperature gas sensors based on metal oxide nanostructures, graphene and 2D transition metal dichalcogenides," Microchim. Acta, vol. 185, no. 4, 2018.

[40] J. Zhang, X. Liu, G. Neri, and N. Pinna, "Nanostructured Materials for Room-Temperature Gas Sensors," Adv. Mater., vol. 28, no. 5, pp. 795-831, 2016

[41] J. P. Cheng, J. Wang, Q. Q. Li, H. G. Liu, and Y. Li, “A review of recent developments in tin dioxide composites for gas sensing application," J. Ind. Eng. Chem., vol. 44, pp. 1-22, 2016.

[42] N. Yamazoe and K. Shimanoe, "Gas Response of Oxide Semiconductor Film Devices under Control of Diffusion and Reaction Effects," Procedia Chem., vol. 1, no. 1, pp. 658-661, 2009.

[43] G. Sakai, N. Matsunaga, K. Shimanoe, and N. Yamazoe, "Theory of gas-diffusion controlled sensitivity for thin ${ }^{\circledR} \mathrm{lm}$ semiconductor gas sensor," Sensors Actuators B Chem., vol. 80, pp. 125-131, 2001.

[44] Z. Yong, V. Mata, and A. E. Rodrigues, "Adsorption of carbon dioxide at high temperature-a review," Sep. Purif. Technol., vol. 26, no. 2, pp. 195-205, 2002.

[45] A. Lopez Aldaba, D. Lopez-Torres, C. Elosua, J.-L. Auguste, R. Jamier, P. Roy, F. J. Arregui, and M. Lopez-Amo, "SnO2-MOFFabry-Perot optical sensor for relative humidity measurements," Sensors Actuators, B Chem., vol. 257, pp. 189-199, 2018.

[46] T. M. Monro, S. Warren-Smith, E. P. Schartner, A. Franois, S. Heng, H. Ebendorff-Heidepriem, and S. Afshar, "Sensing with suspended-core optical fibers," Opt. Fiber Technol., vol. 16, no. 6, pp. 343-356, 2010

[47] A. Lopez-Aldaba, A. M. R. Pinto, M. Lopez-Amo, O. Frazão, J. L. Santos, J. M. Baptista, H. Baierl, J. L. Auguste, R. Jamier, and P. Roy, "Experimental and numerical characterization of a hybrid fabry-Pérot cavity for temperature sensing," Sensors (Switzerland), vol. 15, no. 4, pp. 8042-8053, 2015.

[48] A. Lopez-Aldaba, J.-L. Auguste, R. Jamier, P. Roy, and M. LopezAmo, "Simultaneous and quasi-independent strain and temperature sensor based on microstructured optical fiber," vol. 36, no. 4, p. 103233I, 2017. 
[49] M. Bravo, A. M. R. Pinto, M. Lopez-Amo, J. Kobelke, and K. Schuster, "High precision micro-displacement fiber sensor through a suspended-core Sagnac interferometer," Opt. Lett., vol. 37, no. 2, p. $202,2012$.

[50] P. C. Beard and T. N. Mills, "Extrinsic optical fibre ultrasound sensor using a thin polymer film as a low finesse Fabry-Perot interferometer," Appl. Opt., vol. 34, no. 4, pp. 663-675, 1996.

[51] D. Lopez-Torres, C. Elosua, J. Villatoro, J. Zubia, M. Rothhardt, K. Schuster, and F. J. Arregui, "Enhancing sensitivity of photonic crystal fiber interferometric humidity sensor by the thickness of SnO 2 thin films," Sensors Actuators B Chem., 2017.

[52] Y. B. Cho, S. H. Jeong, H. Chun, and Y. S. Kim, "Selective colorimetric detection of dissolved ammonia in water via modified Berthelot's reaction on porous paper," Sensors Actuators, B Chem., vol. 256, pp. 167-175, 2018.

[53] M. A. Duguay, Y. Kokubun, T. L. Koch, and L. Pfeiffer, "Antiresonant reflecting optical waveguides in $\mathrm{SiO} 2-\mathrm{Si}$ multilayer structures," Appl. Phys. Lett., vol. 49, no. 1, pp. 13-15, 1986.

[54] R. Bise and R. Windeler, "Tunable photonic band gap fiber," Opt. Fiber, vol. 67, pp. 466-468, 2002.

[55] S. Rota-Rodrigo, A. López-Aldaba, R. A. Pérez-Herrera, M. Del Carmen López Bautista, O. Esteban, and M. López-Amo, "Simultaneous measurement of humidity and vibration based on a microwire sensor system using fast fourier transform technique," $J$. Light. Technol., vol. 34, no. 19, pp. 4525-4530, 2016.

[56] D. Lopez-Torres, C. Elosua, J. Villatoro, J. Zubia, M. Rothhardt, K Schuster, and F. J. Arregui, "Photonic crystal fiber interferometer coated with a PAH/PAA nanolayer as humidity sensor," Sensors Actuators, B Chem., vol. 242, pp. 1065-1072, 2016.

[57] D. Lopez-Torres, A. Lopez-Aldaba, C. Elosua, J. L. Auguste, R. Jamier, P. Roy, M. Lopez-Amo, and F. J. Arregui, "Enhancement of the Sensitivity of a Volatile Organic Compounds MOF-Sensor by Means of Its Structure," Proceedings, vol. 1, no. 4, p. 451, 2017.

Diego López-Torres: received the M.S. degree in Electrical and Electronic Engineering in 2012 and his master's degree in communications in 2014 from the Public University of Navarra (UPNA), respectively. Currently, he is doing his Ph.D at Public University of Navarra with a scholarship of this university.

Aitor Lopez-Aldaba: was born in Navarra, Spain, in July 1988. He received the, Telecommunication Engineering degree from the Universidad Pública de Navarra, Navarra, in 2014. In 2013, he joined the Optical Communications Group, Department of Electrical and Electronic Engineering, Universidad Pública de Navarra. His research interests include fiber optic lasers, optical amplifiers, optical fiber sensor networks, photonic crystal fibers and chemical fiber optic sensors.

Cesar Elosúa Aguado: received his MS degree in electrical and electronic engineering from the Public University of Navarre (UPNA, Pamplona, Spain) in 2004. In the same year, he obtained a scholarship from the Science and Technology Spanish Ministry and he joined the optical fiber sensor group at UPNA. During 2008, he was a visiting Ph.D. student at the University of Limerick and at the City University of London. He became a lecturer of this department in 2009, receiving his $\mathrm{PhD}$ degree in the next year. His research interests include optical fiber sensors and networks, organometallic chemistry and data mining techniques.

Raphael Jamier: was born in Périgueux, France, in 1981. He received the Ph.D. degree in 2007 from the University of Limoges, France. Since 2008, he has been an Assistant professor at XLIM research institute / University of Limoges, where he has been engaged in design, fabrication and characterisation of specialty optical fibers. His current research activities include the design, fabrication and characterization of photonic crystal fibers for high-power generation at unconventional spectral domains (in particular in the midinfrared wavelengths). He is also the Deputy Director of the Physics Department of the University of Limoges since 2012. -

He has 27 articles as co-author/author in refereed journals, 58 papers in internationally recognized conferences with peerreview system and 2 patents.

Jean-Louis Auguste: received a $\mathrm{PhD}$ degree in Optical and High Frequency of Telecommunications from the University of Limoges (France) in 2001. During his thesis, the main areas of activity have been involved theory, design and experimental investigation on optical fibres and more particularly on a design and fabrication of high negative chromatic dispersion fibre. Since December 2000, he is a CNRS Engineer at Xlim research institute where he was, until 2012, in charge (Process Manager) of the research and development around fabrication of optical fibres - guide structure (PCF) and materials for optical fibres with recent developments around glass synthesis thanks to a European project (VORTEX) that he manages. He works in strong collaboration with researchers of the Fibre Group and is associated to ANR and other European Projects like researcher from Ceramic Laboratory to develop new topics mixing optical glass development and optical fibre applications. By this way in collaboration with researcher from SPCTS (Ceramic Laboratory) he manages a new research project at Xlim around 'original glasses for optical fibre applications'. He has authored or co-authored 45 publications in international journals with referees and 43 papers in international conferences with referees including several invited papers and international seminars plus 4 patent applications. In 2010, he has obtained the degree of HDR, highest diploma of University and giving him the possibility to be Research Director for PhD students. A part of his activity is dedicated to teaching and training students from University and school engineering.

Philippe Roy: was born in May 1971 in Bellac (France) and received his $\mathrm{Ph}$ Degree in Microwave Electronics and Optoelectronics (speciality Photonics and Electronics Systems) in 1997 in the University of Limoges. He is now a CNRS senior researcher and head of Fibre Photonics group at XLIM, which is a mixed laboratory of University of LIMOGES and CNRS. Since 1998, he is involved in design, fabrication and characterisation of Photonic Crystal fibres (PCFs). More recently, he developed specialty and composite fibres mainly dedicated to advanced fibre sensor systems and to very high power fibre lasers. He develops rare earth doped fibre with complex structure based on an aperiodic design to reach higher power levels without modal instabilities and/or nonconventional emitted spectrum, from visible to $\mathrm{THz}$ domain.

Manuel López-Amo (M'91-SM'98) is a full professor in photonics at the Electrical and Electronic department of Universidad Pública de Navarra (Spain) since 1996. He is the head of the optical communications group of this department. 
He has been Chairman of the Optoelectronic Committee of Spain. He has been the director of the Engineering Faculty and of the Electrical and Electronic department of Universidad Pública de Navarra. He has been the leader of more than 60 research projects and he has coauthored more than 300 works in international refereed journals and conferences related with fiber-optic networks, fiber-optic sensors, fiber-optic amplifiers and lasers and integrated optics. He has supervised $16 \mathrm{PhD}$ theses about Photonics. He is a member of the technical committees of the International Conference on fiber optic sensors (OFS) and the European Workshop on optical fiber sensors (EWOFS), among others. Professor Lopez-Amo is senior member of the IEEE.

Francisco J. Arregui is a Full Professor in the Electrical and Electronic Engineering Department at the Public University of Navarre (Pamplona, Spain). He was part of the team that fabricated the first optical fiber sensor by means of the layer- by-layer self-assembly method at Virginia Tech (Blacksburg, VA, USA) in 1998. He is the author of around 400 scientific journal and conference publications, most of them related to optical fiber sensors based on nanostructured coatings. Prof. Arregui has been Associate Editor or Guest Editor of the journals "Sensors", "IEEE Journal of Selected Topics in Quantum Electronics", "IEEE Sensors Journal", and "Journal of Sensors". This last journal, Journal of Sensors (Hindawi), was founded in 2007 by Prof. Arregui, who served as the Editor-inChief from 2007 to 2011. He is also the Editor of the book "Sensors Based on Nanostructured Materials" (Springer) and "Optochemical Nanosensors" (Taylor \& Francis). 